\title{
Preliminary investigation into the feasibility of combining satellite and GPS data to identify pasture growth and grazing
}

\author{
Simon J.R. WOODWARD ${ }^{1 *}$, Mark B. NEAL ${ }^{1}$ and Peter S. CROSS ${ }^{2}$ \\ ${ }^{1}$ DairyNZ Ltd, Pricate Bag 3221, Hamilton 3240, New Zealand \\ ${ }^{2}$ Livestock Improvement Corporation (LIC), Private Bag 3016, Hamilton 3240, New Zealand
}

*Corresponding author: simon.woodward@dairynz.co.nz

\begin{abstract}
Regular estimation of pasture availability is a timeconsuming on-farm task, but one that is vital for good grazing management. The ability to automate this task is, therefore, highly valuable. Combining satellite sensing of pasture mass with global positioning for herd location provides raw data that can potentially be used to automatically estimate pasture mass, pasture growth and pasture grazing events across a farm. The feasibility of automatically obtaining and processing this information was demonstrated on a Waikato dairy farm from 22 October 2018 to 21 February 2019 (123 days), with 13 global positioning collars recording the location of grazing mobs 16 times per hour on average, in a dairy herd of initially 380 animals. Satellite sensing of pasture cover over the same period was only possible on 16 days during this period, with November being particularly cloudy, resulting in fewer pasture cover estimates. A non-linear regression model was constructed with parameters representing initial pasture cover, average pasture growth rate through time, pasture growth differences between paddocks, pasture disappearance rate relative to the density of cow GPS samples, and an ungrazeable residual. A Bayesian approach was used to infer the model parameters from the satellite-measured pasture cover data. This allowed interpolation of pasture mass through the whole period with an RMSE of $225 \mathrm{kgDM} / \mathrm{ha}$, as well as identifying growth rate differences between paddocks, which may provide a useful basis for improved pasture management. Rough estimates of cow average daily pasture disappearance were also made, which peaked at $20 \mathrm{kgDM} / \mathrm{d}$ in November, falling to $5 \mathrm{kgDM} / \mathrm{d}$ by February. This pilot study demonstrated the feasibility of combining satellite pasture cover data with herd location data from a small number of GPS collars to infer pasture growth rates in individual paddocks through time.
\end{abstract}

Keywords: pasture mass, satellite, remote sensing, GPS, GNSS, low-power wide-area network (LPWAN)

\section{Introduction}

Grazed pasture is the basis of profitable dairy systems in temperate regions such as New Zealand, Australia and
Ireland (Neal et al. 2019). Optimal use of this resource requires regular measurement of pasture availability (usually expressed in $\mathrm{kgDM} / \mathrm{ha}$ ), as well as estimation of future growth rates (Fulkerson et al. 2005; Hanrahan et al. 2017; Beukes et al. 2018). Current methods of onfarm pasture measurement include: visual assessment; calibrated rising-plate meter measurement (RPM); and vehicle-mounted sensors (L'Huillier \& Thomson 1988; Dalley et al. 2009; Eastwood et al. 2009). However, such methods remain time consuming and labourintensive.

Recently, the feasibility of satellite-based estimation of pasture availability has been assessed in several countries (Eastwood et al. 2009; Mata et al. 2011; Ali et al. 2016), including the development of the LIC SPACE ${ }^{\mathrm{TM}}$ system used in the current paper (Anderson \& McNaughton 2018). These studies have shown that, with suitable local calibration equations, accuracy can be on a par with, or better than, proximate measurement techniques (c.f. Xu \& Katchova 2018), with root meansquared error (RMSE) of the prediction of pasture mass reported as $200 \mathrm{kgDM} / \mathrm{ha}$ by Mata et al. (2011) and 329 $\mathrm{kgDM} / \mathrm{ha}$ by Anderson and McNaughton (2018).

In order to estimate pasture growth rates from these data, regular measurements are required, as well as accurate records of the timing and location of grazing events (Eastwood et al. 2009; Romera et al. 2010). However, satellite measurements are often hindered by frequent cloud cover in temperate pastoral regions, while grazing records are often incomplete or nonexistent. Romera et al. (2010) addressed the issue of missing pasture data by using a pasture growth model to interpolate between data points, although their system still required relatively complete grazing information to be provided.

Currently, most pastoral dairy farms in New Zealand and Australia do not keep paper or electronic records of herd locations and paddocks grazed. The PastureBase Ireland (PBI) online database is exceptional in this regard, by motivating regular recording of pasture cover and grazing (Hanrahan et al. 2017). However, GNSS (Global Navigation Satellite System) technologies, including GPS (Global Positioning Systems) have continued to improve over the last few decades, and researchers have started to assess their use for automated herd location (Haultain 2014). Alongside this, the 


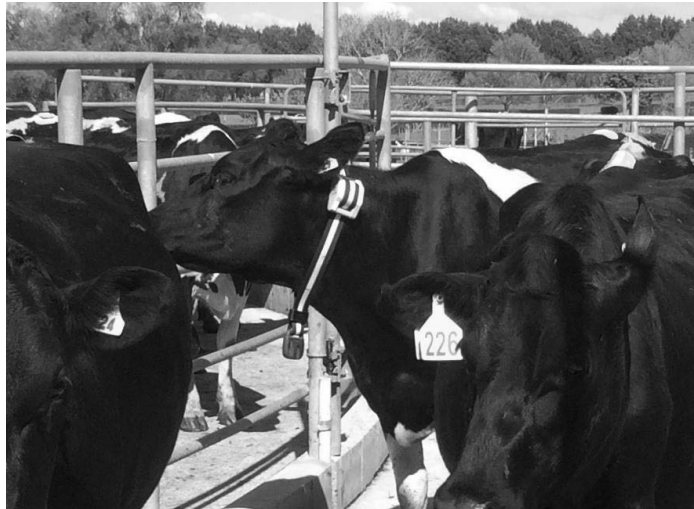

Figure 1

GPS device (digitAnimal) collar on middle cow.

rapid improvement in low-power wide-area networks (LPWAN) have recently enabled commercial feasibility of real-time reporting of herd position. LPWAN systems can deliver data from the cow to the cloud with longer transmission range, much longer battery life, and much lower cost, compared with traditional cellphone-based data transmission services such as General Packet Radio Service (GPRS). LPWAN networks such as Sigfox, NB-IoT, LoRaWAN and Cat M1 now cover large parts of rural New Zealand, with future expansion promising to penetrate even the hillier regions of New Zealand. Where those networks do not reach, the farmer can install their own low-cost base station, or in the near future, use satellite-based LPWAN services. Hence, automated positioning devices, located on cows, are now commercially feasible for automatically recording cow position and making that data available for the determination of paddocks being grazed.

We present preliminary results from a pilot study that aimed to assess the feasibility of combining incomplete satellite pasture cover data with herd location data from GPS collars. This combination could allow us to interpolate across the gaps in the satellite data to complete the pasture cover time series for each paddock on a farm. The completed time series could then be used to estimate pasture growth rate through time, pasture growth differences between paddocks, and pasture disappearance associated with grazing.

\section{Materials and Methods}

\section{Site details}

The trial was carried out at Livestock Improvement Corporation (LIC) 'Innovation Farm', which is a commercial and research dairy farm in the Waikato region of New Zealand. The region has a temperate climate, with warm humid summers and mild winters and an annual average rainfall of $1300 \mathrm{~mm}$. The farm consists of 105 hectares ( 97 hectares effective) of flat land at an elevation of $40 \mathrm{~m}$ above sea level, divided into 50 paddocks ( 0.1 to 2.9 hectares). Eighty percent of the farm is organic soil type (peat), with the remaining area being Allophanic, Brown, Gley or Granular. Irrigation is not used. Production was $123,114 \mathrm{~kg}$ of milksolids (kg/MS) in the 2017/18 season.

The data collection period ran from October 2018 to February 2019, with initially 372 animals on the farm (cross breed with average 8/16 Friesian and 8/16 Jersey). Animals included 281 cows in milk reducing to 236 in late summer, 79 heifers which left in November; and 12 bull calves which left in February. Cows were often split into several mobs (e.g. late calvers, treatment mob), and grazed in several paddocks simultaneously.

\section{Data collection}

GPS

Two types of GPS devices were tested: the 'digitAnimal' and 'Digital Matter Oyster' (Sigfox, Labège, France). These both used the Sigfox LPWAN, and were configured to acquire GPS position and send that position to the cloud, approximately once an hour. The 'digitAnimal' GPS devices are specially designed for use on animals, including cattle. The 'Oyster' GPS devices are designed for general purpose use (e.g. mounting against a flat surface on a vehicle) and so were attached to commercially available weighted cattle collars (Allflex NZ Ltd, Palmerston North NZ). The weight keeps the collars from rotating, preventing the device from being damaged against feeding and drinking troughs. For standardisation, the collar and weight supplied with the 'digitAnimal' devices was replaced with the same collars and weights used with the 'Oyster' GPS devices.

In the pilot study, fifteen GPS collars (6 'digitAnimal' and 9 'Oyster') were fitted to randomly selected cows in the milking herd (Figure 1). The collars remained fitted to the same cows throughout the trial period, regardless of whether the cow remained part of the main milking herd or moved to a treatment herd. Unfortunately, the number and sizes of herds grazing each day, and the presence of the GPS cows within those herds was not recorded. Manual records were kept of paddocks grazed after each milking. These records were found to be less accurate than the GPS location algorithm, however, and so could not be used for validation.

Thirteen of the collars (6 'digitAnimal' and 7 'Digital Matter Oyster') were active during the sampling and analysis period from 22 October 2018 to 21 February 2019. Jointly these provided an average of 16 locations per hour combined across all 13 devices, each giving cow position (longitude and latitude) to within 10-m accuracy (Haultain 2014) (although outlier positions up to $50 \mathrm{~m}$ were occasionally recorded). These positions were first compared with digitised paddock boundaries to identify the paddock/paddocks currently being 
grazed. Paddock identification was carried out using 'simple features' (sf) spatial analysis, and outliers were removed using 'density-based spatial clustering' (dbscan), in R ( $\mathrm{R}$ Core Team 2014). This removed $5.2 \%$ of the 'digitAnimal' locations and $3.2 \%$ of the 'Digital Matter Oyster' locations, some of which were when cows were in the milking shed or farm races. The GPS signal was not affected by climatic conditions such as cloud or sun, heat or cold. The stocking density and grazing time in each paddock were assumed to be proportional to the fraction of GPS locations identified for each paddock on each day. So, for example, if a paddock recorded $20 \%$ of the successful GPS locations on a particular day, this was assumed to represent $20 \%$ of the total number of cows, $20 \%$ of the total grazing time (i.e. 1 day), or an equivalent combination of both.

As this was a pilot study for the technology, the number of collars and frequency of sampling was not optimised. A smaller number of collars with less frequent sampling could be sufficient in some situations (c.f. Haultain 2014). Whether 13 active collars with approximately hourly sampling was sufficient for the current trial (which had multiple, sometimes smaller, herds) is implicitly tested in the RMSE of the fitted model residuals. If the GPS data give insufficient information about the location and density of cows, the model RMSE will be unacceptable.

\section{Satellite}

Pasture cover was measured using the Livestock Improvement Corporation (LIC) SPACETM satellite product (Anderson \& McNaughton 2018), which converts satellite images to per-paddock measurements of pasture cover. The satellite images were sourced mainly from the high-resolution, multispectral Sentinel-2, RapidEye and Planetscope constellations (10 $\mathrm{m}, 5 \mathrm{~m}$ and $3 \mathrm{~m}$ resolution, respectively), which provide geo-referenced raster data in the red, green, blue and near-infrared (RGBN) spectral ranges (Baloloy et al. 2018). These data are used to calculate the Normalised Difference Vegetation Index (NDVI) in each grid cell, which estimates photosynthetic activity as the scaled difference between the absorption of photosynthetically active radiation (PAR), which is absorbed by green plants, and near-infrared radiation (NIR), which is reflected by green plants (Ali et al. 2016). A standard calibration equation between NDVI and proximate measurements of pasture mass was used, as described in Anderson and McNaughton (2018). The accuracy of the satellite measurements relative to other measurement techniques has been assessed in other studies, as mentioned in the Introduction, and is outside the scope of the current study.

Due to cloud and other atmospheric conditions, pasture cover data were only successfully measured on
16 days during the 123-day analysis period (see Figure 2), with 767 non-missing data values in total. Clearly this is insufficient for pasture management purposes. The challenge, therefore, is to infer the pasture cover continuously between the successful measurements. To do this requires modelling based on grazing information (Romera et al. 2010). In the current study, the GPS collars provide the grazing information automatically.

\section{Modelling}

The cow location data were used as an input to a non-linear regression model, which, when calibrated to the incomplete satellite measurements, allowed interpolation of daily pasture cover in 49 paddocks over the whole period (excluding Paddock 4 which recorded no grazing). In the model, the key quantities of interest (e.g. initial pasture mass, pasture growth rate, relative disappearance rate) were represented directly as calibration parameters to be inferred. This is in contrast to mechanistic pasture growth models such as those used by Romera et al. (2010) and Vogeler and Chicota (2015), which leverage detailed knowledge of pasture processes, but require extensive site-specific weather and/or soil information.

The regression model was constructed as follows: pasture growth was modelled as an 'average' pasture growth rate $\left(g_{j}\right)$ in each of 9 time periods $j$, multiplied by a growth rate factor $\left(f_{\mathrm{i}}\right)$ for each paddock $i$. Time periods were initially defined as one week, and then aggregated until each period included at least one pasture cover observation. Pasture grazing was modelled using the exponential-decline model of McCall et al. (1986), with a parameter $(k)$ representing pasture disappearance per cow per hectare per day above an ungrazeable residual $(u)$. Inputs to the model were the fraction of total GPS locations received $\left(p_{\mathrm{i}, \mathrm{t}}\right)$, the total number of cows $\left(n_{\mathrm{t}}\right)$ on each day $t$, and the paddock area $\left(a_{\mathrm{i}}\right)$. Daily change in pasture cover $\left(c_{\mathrm{i}, \mathrm{t}}\right)$ was then calculated as

$$
\begin{aligned}
& c_{\mathrm{i}, \mathrm{t}}-c_{\mathrm{i}, \mathrm{t}-1}=g_{\mathrm{j}} * f_{\mathrm{i}}-\left(1-\exp \left(-k * p_{\mathrm{i}, \mathrm{t}} * n_{\mathrm{t}} / a_{\mathrm{i}}\right)\right) \\
& * \max \left(0, c_{\mathrm{i}, \mathrm{t}-1}-u\right) \\
& \text { [Equation } 1]
\end{aligned}
$$

This equation represents a non-linear regression model with 109 parameters. The full list of model parameters for calibration (including their permitted ranges) was:

- Initial pasture cover in each paddock $\left(c_{\mathrm{i}, 0}, 0-4000\right.$ $\mathrm{kgDM} / \mathrm{ha})(49)$

- 'Average' pasture growth rate in each period $\left(g_{\mathrm{j}},-20\right.$ $100 \mathrm{kgDM} / \mathrm{ha} / \mathrm{d})(9)$

- Relative pasture growth rate in each paddock $\left(f_{\mathrm{i}}\right.$, 0.0-2.0) (49)

- Grazing constant $(k, 0.001-1.000 \mathrm{ha} / \mathrm{cow} / \mathrm{d})(1)$

- Ungrazeable residual (u, 500-2500 kgDM/ha) (1)

From the model inputs and parameters, the model predicts pasture growth and disappearance in each 
31

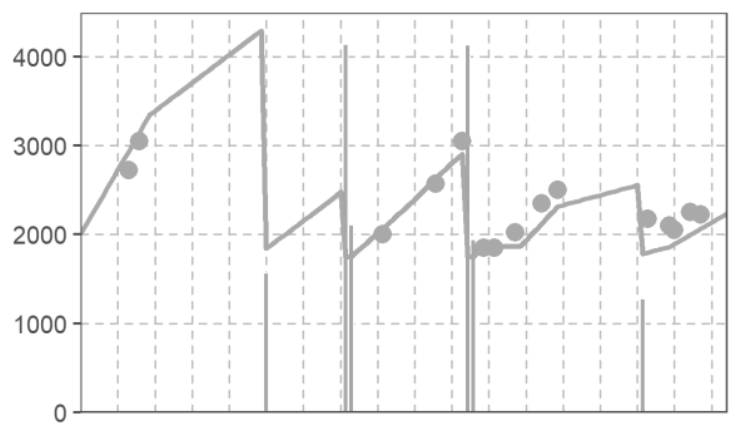

20

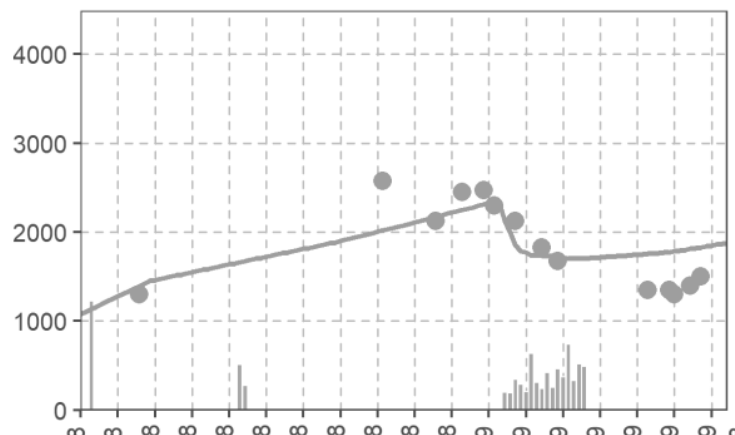

21

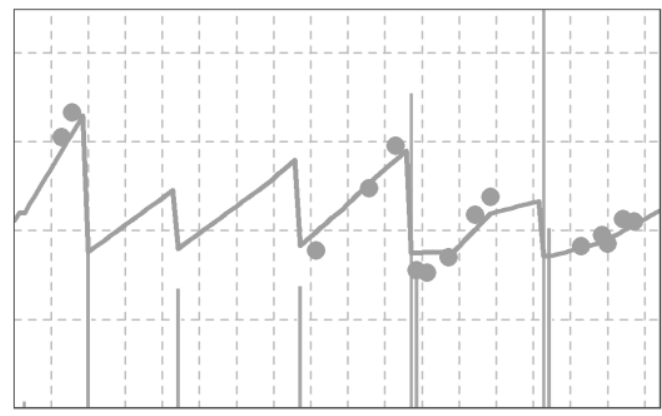

42

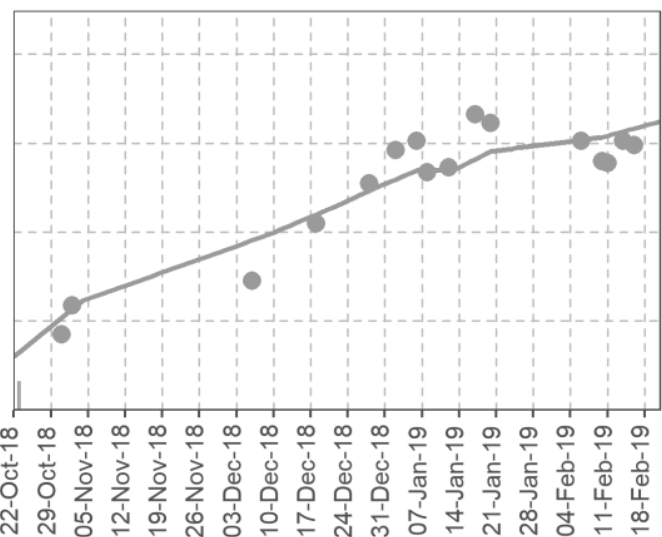

Figure 2 SPACE ${ }^{\mathrm{TM}}$ satellite pasture data ( $\mathrm{kgDM} / \mathrm{ha}$, dots), GPS grazing locations (estimated \% of cow-days $\mathrm{x} 100$, vetical bars), and modelled pasture cover (kgDM/ha, lines), for four paddocks (31,21, 20 and 42). For example, the number of cowdays in paddocks 31 and 21 ranged from $13 \%$ to $45 \%$, and in paddock 20 only from $2 \%$ to $12 \%$ (probably a treatment mob).

paddock in each day. These predictions are compared with the observed pasture cover data (from the satellite). A likelihood function was constructed, assuming that the data had a standard error of $329 \mathrm{kgDM} / \mathrm{ha}$, as estimated by Anderson and McNaughton (2018), and that the residuals were independent and distributed according to a Student's t-distribution with 7 degrees of freedom, based on Jeffreys' arguments regarding the measurement error distributions in real data sets (Jeffreys, 1938). Prior parameter distributions were constructed as beta distributions on the ranges shown above.

Calibrating the model under these assumptions allows the 109 model parameters to be estimated. This was done using the 'DREAM ${ }_{\mathrm{ZS}}$ ' Markov_Chain Monte Carlo algorithm (ter Braak \& Vrugt 2008) as implemented in the 'BayesianTools' package in R, to infer the 'likely' (posterior) joint distribution of the parameters. The inferred posterior distribution allows a thorough uncertainty analysis, but for simplicity, here we report the results for the 'best' (maximum a posteriori, MAP) parameter set only.

\section{Results}

Model predictions using the MAP parameter set matched the satellite data with an RMSE of $225 \mathrm{kgDM} / \mathrm{ha}$. The assumed uncertainty of the satellite measurements was $329 \mathrm{kgDM} / \mathrm{ha}$ (Anderson \& McNaughton 2018), indicating that the model uncertainty was relatively small compared with the measurement uncertainty. The match between observed and modelled pasture cover for four selected paddocks is shown in Figure 2. The vertical bars indicate the estimated daily grazing in each paddock (\% of cow-days) based on the GPS data, which was used to predict pasture disappearance as described in Equation 1. Paddocks 21 and 31 are typical of the majority of the 49 paddocks, and were grazed in a typical rotational pattern. Paddock 20 was grazed for several days in a row by a small treatment mob, as indicated by a cluster of smaller vertical bars. Paddock 42 had a low growth rate and was not grazed after October.

The steepness of the pasture cover predictions (sloping lines) in Figure 2 is the modelled pasture growth rate, which is the combination of the parameters representing per-period 'average' pasture growth rate 


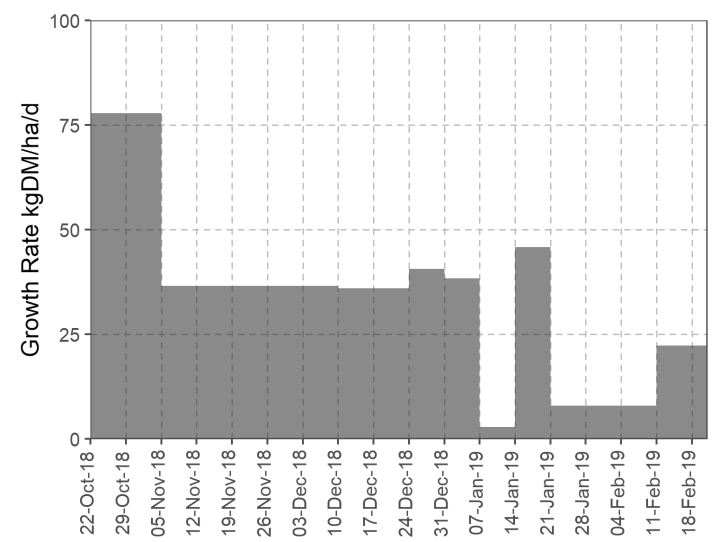

Figure 3 Estimated 'average' pasture growth rate $\left(g_{\mathrm{j}}, \mathrm{kgDM} /\right.$ ha/d) through time. Growth rate was estimated to be $3 \mathrm{kgDM} / \mathrm{ha} / \mathrm{d}$ from 7-14 January. $\left(g_{\mathrm{j}}\right)$ and the per-paddock growth rate multiplier $\left(f_{\mathrm{i}}\right)$ (Equation 1). The predicted values of these parameters are shown in Figure 3 and Figure 4 respectively. As expected, predicted growth rates are highest in October and lowest in January-February. Growth rate was estimated to be very low $(3 \mathrm{kgDM} / \mathrm{ha} / \mathrm{d})$ during one week in January. Periods without pasture cover data were aggregated so, for example, a single growth rate was estimated for the whole of November.

Bayesian calibration allows us to estimate the uncertainty of the inferred model parameters. Pasture growth rate in each time period $\left(g_{j}\right)$, was estimated with standard errors (standard deviation of the marginal posterior parameter distribution) in the range 2.3 to 7.1 (mean 5.7) $\mathrm{kgDM} / \mathrm{ha} / \mathrm{d}$. Although a full analysis has not yet been carried out, the small size of these errors probably reflects consistency in the satellite measurements of pasture cover and the relatively large number of paddocks (up to 49) measured at each point in time.

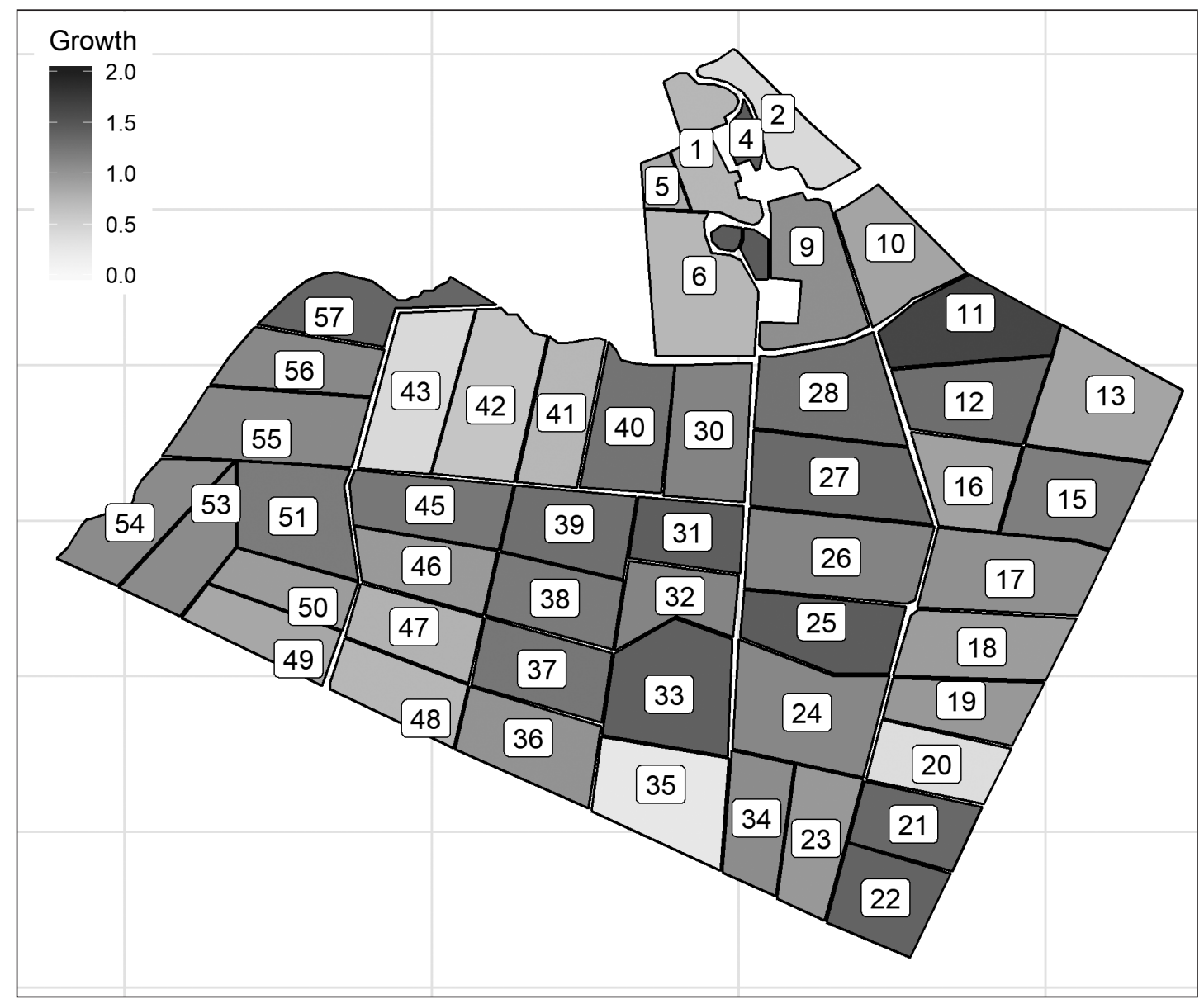

Figure 4 Farm GIS map showing paddock names. Shading indicates the estimated growth rate of each paddock $\left(f_{\mathrm{i}}\right)$ relative to the predicted average in Figure 3 (i.e. values greater than 1 indicate a growth rate greater than average, and values less than 1 indicate a growth rate less than average). 


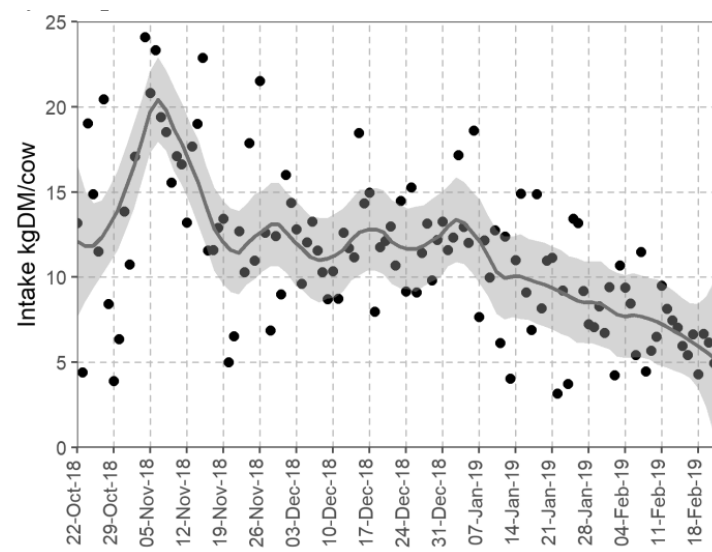

Figure 5 Estimated average daily pasture disappearance per cow (kgDM/cow, dots) with fitted curve and 95\% confidence interval (grey shading).

The slopes of the pasture cover predictions in Figure 2 suggest that pasture growth was higher in Paddocks 21 and 31, and lower in Paddocks 20 and 42. These differences are represented by the relative pasture growth rate parameters $\left(f_{\mathrm{j}}\right)$, which likely represent differences in soil type, fertility, and pasture vigour. This aspect of the model provides a useful diagnostic for paddock performance. The growth rate multipliers for all paddocks are shown in Figure 4, and suggest that relatively productive and less-productive paddocks tend to be clustered together. For example, there is a cluster of productive paddocks around Paddock 31. Conversely, there are several less productive paddocks near Paddock 42.

Relative growth rate between paddocks $\left(f_{\mathrm{i}}\right)$ was estimated with standard errors in the range 0.08 to 0.27 (mean 0.18). Compared with the pasture growth rate estimates $\left(g_{j}\right)$, these uncertainties are relatively high, probably reflecting the relatively small number of pasture measurements for each paddock (up to 16), combined with uncertainty in the grazing intensity estimated from the GPS collars.

Pasture disappearance is indicated by the decline in pasture cover during grazing (which is indicated by the vertical bars). The rate of pasture removal is proportional to the stocking density (McCall et al. 1986), which is estimated from the total number of animals multiplied by the proportion of GPS locations received from each paddock (Equation 1). Since the number of GPS collars is relatively small, the stocking density is estimated imperfectly. Errors in estimated stocking density are reflected in higher model residuals. Because the model residuals were relatively low, however, this suggests that stocking density was adequately estimated with the number of collars and frequency of samples used in this trial.
The model is also able to estimate pasture disappearance (related to intake) in each grazed paddock, and averaged over all cows (Figure 5). Pasture disappearance rose from $10-15 \mathrm{kgDM} / \mathrm{cow} / \mathrm{d}$ around calving to peak at $20 \mathrm{kgDM} / \mathrm{cow} / \mathrm{d}$ in early lactation, and declined with pasture mass over the summer, to around $5 \mathrm{kgDM} / \mathrm{cow} / \mathrm{d}$ in February, corresponding to increases in the amount of supplement fed.

The pasture disappearance estimates were very variable on a day-to-day basis (Figure 5). Detailed analysis was beyond the scope of the current study but this variation could be either: real, and reflect variation in the available pasture in the paddocks being grazed (c.f. Figure 4); or due to uncertainty in the data analysis, possibly as a result of variable data coverage. Since the satellite measurements of pasture cover are often infrequent (e.g. there were no measurements between 2 November and 6 December), for example, predicted pasture cover, and thus pasture disappearance, may be quite uncertain and/or variable at these times.

\section{Discussion}

The results of this preliminary investigation showed the feasibility of combining incomplete satellite pasture cover data, with GPS location data from collars fitted to a small number of cows, to infer pasture cover daily in each paddock of a pasture-based dairy farm (e.g. Figure 2). This was achieved by calibrating a nonlinear regression model of pasture growth and grazing (Equation 1) to available satellite measurements of pasture cover (available for 16 out of 123 days), with daily grazing intensity by paddock estimated from GPS collars (fitted to 13 out of 372 cows, i.e. 3.5\%). No other model inputs were required apart from total cow numbers daily. Information on fertilisation, herbicide and renovation activities was not required, even though these differed somewhat between paddocks. The trial farm was not irrigated, and so the need for irrigation data is yet to be assessed.

The primary result of data analysis was the interpolated pasture cover (Figure 2), which can potentially be extrapolated into the future somewhat, and is valuable for feed budgeting and grazing management. This is a similar objective to that of Romera et al. (2010), who calibrated a climate-driven, mechanistic pasture growth model to farmer pasture cover data in order to forecast growth up to 28 days into the future. The ability of the current approach to forecast growth is probably more limited, since it cannot respond to weather information.

The analysis also shows the feasibility of estimating the pasture growth rate through time (Figure 3) and the relative growth rate differences between paddocks (Figure 4). These quantities are represented as parameters $\left(g_{\mathrm{j}}\right.$ and $f_{\mathrm{i}}$ respectively) in the model (Equation 1 ), and are estimated by Bayesian calibration to the 
satellite pasture measurements. The inferred growth rate values had low standard errors, and are potentially valuable for highlighting past feed shortages, which may have been due to moisture deficit, for example, leading to management changes in the future. Inferred differences between paddocks, on the other hand, while more uncertain, could be useful for guiding cropping and regrassing decisions, and paddock-specific grazing management.

As well as pasture cover and growth, the model provides rough estimates of cow intake (Figure 5), which is very difficult to measure directly. Such estimates may be useful for diagnosing cow nutrition constraints (reflected in milk yield), and supporting grazing and supplementation planning.

As this was a preliminary investigation, the approach has not been optimised. A number of research questions remain, including how much pasture data, and how many GPS collars, are required to achieve a useful degree of certainty in the results. A minimum of two pasture measurements are probably required in each paddock to estimate growth rate. However, inference based on such a small dataset would probably have high uncertainty. A smaller number of GPS collars, and a lower sampling frequency, may be also possible. Haultain (2014), for example, suggested three collars per herd, each sampling at least once per paddock would be sufficient (twice-daily-milked cows are typically offered two paddocks each day). The situation is more complicated when the herd is split into multiple mobs, including small mobs for calving or treatment cows, as in the current study. Mobs may not always include a representative number of GPS-collared cows, so that predictions of per-paddock grazing intensity could have considerable uncertainty. On the other hand, one advantage of the Bayesian approach used here is the ability to assess the uncertainty of the model predictions in a robust way.

The non-linear regression model used to fit the pasture and grazing data (Equation 1) is illustrative only, and has also not been optimised or compared with alternative models. In the particular, the grazing constant $(k)$ and the ungrazeable residual $(u)$ are relatively simplistic representations of grazing behaviour. It is possible that assuming a constant value for $u$ is too restrictive, and results in the $k$ parameter becoming relatively unimportant. An alternative approach could be to allow different values of $u$ (i.e. $u_{\mathrm{j}}$ ) in each time period.

\section{Conclusion}

This study successfully demonstrated the potential of this approach to provide continuous, detailed and accurate pasture information to help farmers optimise grazing management and feed planning. The satellite and GPS technologies used are already available at low cost, and the data stream has the potential to be completely automated, apart from the requirements: (1) to fit the GPS devices and replace batteries/devices every few years; and (2) to enter the total number of cows. As well as providing the basis for improved grazing management, such a data stream would also be valuable to integrate into other farm intelligence systems, such as those targeting pasture fertilisation and renovation.

\section{ACKNOWLEDGEMENTS}

This work was funded by New Zealand dairy farmers through DairyNZ and LIC.

\section{REFERENCES}

Ali I, Cawkwell F, Dwyer E, Barrett B, Green S. 2016. Satellite remote sensing of grasslands: from observation to management. Journal of Plant Ecology 9(6); 649-671.

Anderson G, McNaughon L. 2018. Validation of a satellite pasture measurement system. Proceedings of the 8th Australasian Dairy Science Symposium, 21-23 November 2018, Palmerston North, New Zealand. Accessed on 26/7/2019 at https://adss2018. sched.com/event/GJCw/validation-of-a-satellitepasture-measurement-system

Baloloy AB, Blanco AC, Candido CG, Argamosa RJL, Dumalag JBLC, Dimaplis LLC, Paringit EC. 2018. Estimation of mangrove forest aboveground biomass using multispectral bands, vegetation indices and biophysical variables derived from optical satellite imageries: Rapideye, Planetscope and Sentinel-2. ISPRS Annals of the Photogrammetry, Remote Sensing and Spatial Information Sciences $I V-3, \quad 29-36 . \quad$ https://doi.org/10.5194/isprs-annalsIV-3-29-2018

Beukes PC, McCarthy S, Wims CM, Gregorini P, Romera AJ. 2018. Regular estimates of herbage mass can improve profitability of pasture-based dairy systems. Animal Production Science 59(2): 359-367. https://doi.org/10.1071/AN17166

Dalley D, Clark D, Pairman D, Dynes R, Yule I, King W, Mata G. 2009. Technologies for measuring grass/crops. Proceedings of the South Island Dairy Event pp. 134-151. http://side.org.nz/wpcontents/uploads/2014/05/TECHNOLOGIES-FORMEASURING,1.pdf

Eastwood CR, Mata G, Handcock RN, Kenny S. 2009. Evaluating satellite-based pasture measurement for Australian dairy farmers. Precision Livestock Farming: Proceedings of the Joint International Agriculture Conference, 6-8 July 2009, Wageningen, The Netherlands. Accessed on 26/7/2019 at https://pdfs.semanticscholar.org/ e38b/2a02ab22061f80a6c57f4a615098feb84d5f.pdf 
Fulkerson WJ, McKean K, Nandra KS, Barchia IM. 2005. Benefits of accurately allocating feed on a daily basis to dairy cows grazing pasture. Australian Journal of Experimental Agriculture 45(4): 331-336.

Hanrahan L, Geoghegan A, O'Donovan M, Griffith V, Ruelle E, Wallace M, Shalloo L. 2017. PastureBase Ireland: A grassland decision support system and national database. Computers and Electronics in Agriculture 136: 193-201.

Haultain J. 2014. Ranking paddock performance using data automatically collected in a New Zealand dairy farm milking system. MSc thesis, Massey University, Palmerston North, New Zealand. Accessed on 26/7/2019 at https://mro.massey.ac.nz/bitstream/ handle/10179/5423/02_whole.pdf

Jeffreys H. 1938. The law of error and the combination of observations. Philosophical Transactions of the Royal Society (London) Series A 237: 231-271. doi:10.1098/rsta.1938.0008

L'Huillier PJ, Thomson NA. 1988. Estimation of herbage mass in ryegrass/white clover dairy pastures. Proceedings of the $49^{\text {th }}$ New Zealand Grassland Association: 117-122.

Mata G, Purdie N, Handcock RN, Dalley D, Ota N, Rossi L. 2011. Validating satellite monitoring of dairy pastures in Canterbury with Lincoln University Dairy Farm and commercial farm data. Proceedings of the New Zealand Grassland Association 73: 109114.

McCall DG, Townsley RJ, Bircham JS, Sheath GW. 1986. The interdependence of animal intake, pre- and post-grazing mass and stocking density. Proceedings of the New Zealand Grassland Association 47: 255261.

Neal MB, Woodward SJR, Dela Rue BT. 2019. Identifying the pasture potential for New Zealand dairy farms. Journal of New Zealand Grasslands 81: 235-238.

R Core Team. 2014. R: a language and environment for statistical computing. R Foundation for Statistical Computing, Vienna, Austria. Accessed: 13/5/2019 from: http://www.R-project.org

Romera AJ, Beukes P, Clark D, Levy H, Tait A. 2010. Use of a pasture growth model to estimate herbage mass at a paddock scale and assist management on dairy farms. Computers and Electronics in Agriculture 74(1): 66-72.

ter Braak CJF, Vrugt JA. 2008. Differential evolution Markov Chain with snooker updater and fewer chains. Statistical Computing 18: 435-446. http://doi. org/10.1007/s11222-008-9104-9

Vogeler I, Chicota R 2015. Deriving seasonally optimal nitrogen fertilization rates for a ryegrass pasture based on agricultural production systems simulator modelling with a refined AgPasture model. Grass and Forage Science 71(3): 353-365. https://oi. org $/ 10.1111 /$ gfs. 12181

Xu C, Katchova A. 2018. Predicting soybean yield with NDVI using a flexible Fourier Transform Model. Southern Agricultural and Applied Economics Association's 2018 Annual Meeting, 3-6 February 2018, Jacksonville, Florida, USA. Accessed on 30/7/2019 at https://ideas.repec.org/p/ags/ saea18/266693.html 